\title{
CD8+ mycosis fungoides: A wolf in sheep's clothing?
}

\section{Asmae Abdelmouttalib', Sanae Sialiti', Soumaya Hamich', Kawtar Znati Mariame Meziane' ${ }^{1}$, Nadia Ismaili' ${ }^{1}$, Leila Benzekri' ${ }^{1}$, Karima Senouci'} ${ }^{1}$ Dermatology and Venereology Department, Mohamed V University in Rabat, Morocco, ${ }^{2}$ Anatomopathology Department,
Mohamed V University in Rabat, Morocco

Corresponding author: Asmae Abdelmouttalib MD, E-mail: abdelmouttalibasmae@gmail.com

Sir,

$\mathrm{CD}^{+}$mycosis fungoides $(\mathrm{MF})$ is a rare form of $\mathrm{MF}$ with an indolent course. Herein, we report a rare case of CD8+ fungoid mycosis preceded by lymphomatoid papulosis type $\mathrm{D}$ with an aggressive course.

A 36-year-old female presented with several papular lesions on the trunk and extremities with a relapsing-remitting course. Histopathology and an immunohistochemical study confirmed CD8-positive lymphomatoid papulosis type D and methotrexate at $25 \mathrm{mg} /$ week was initiated. After a temporary clinical improvement, the lesions worsened, became infiltrated, and grouped as vaguely annular and angular patches with serpiginous borders (Fig. 1). A second scalp biopsy was performed and a diagnosis of $\mathrm{CD} 8^{+} \mathrm{MF}$ was established. An extension workup was normal, and MF was classified as stage IB. PUVA therapy was started with acitretin at $25 \mathrm{mg} /$ day. After four weeks from the beginning of treatment, the patches completely disappeared but with the concomitant appearance of four subcutaneous tumors. The evolution was spectacular in fifteen days, with the tumors rapidly increasing in size, becoming ulcerative and necrotic, and one being localized in the left cervical area compressing the upper respiratory tract (Fig. 2). A subsequent biopsy revealed massive epidermal and dermal large cell infiltration (Fig. 3a); the tumor cells were positive for CD3, CD8, and CD7 (Fig. 3b) and negative for CD4, CD5, CD3, CD2, and CD30. Antigen Ki-67 was expressed by more than $80 \%$ of T-cells (Fig. 3c). A cerebral and thoraco-abdominal CT scan revealed multiple axillary lymph nodes with hypermetabolism on a PET scan. An osteomedullar biopsy was normal, and lactate dehydrogenase (LDH) was increased to 358

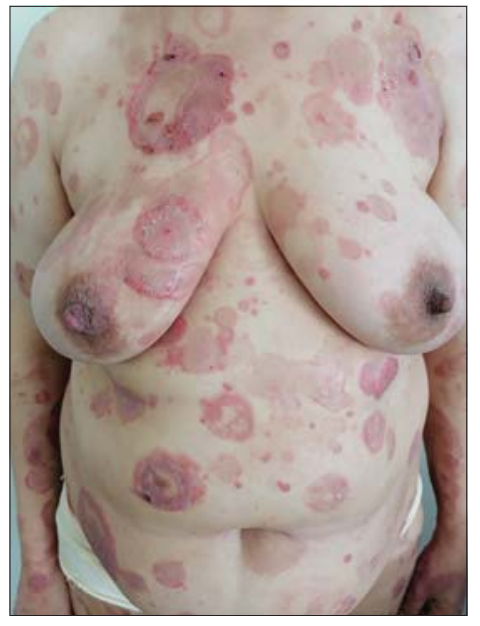

Figure 1: Erythematous and scaly patches with arciform borders disseminated all over the skin.

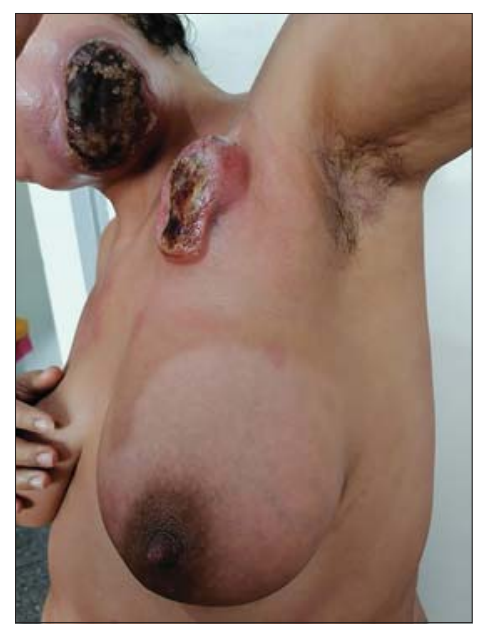

Figure 2: Ulcero-necrotic tumors that appeared after four weeks of RePUVA therapy.

U/L. Chemotherapy was performed, but the patient died after two cycles of CHOEP.

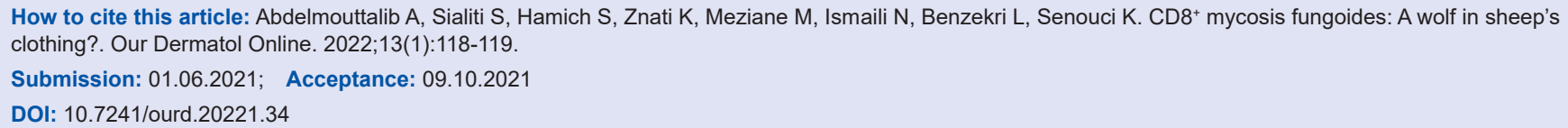




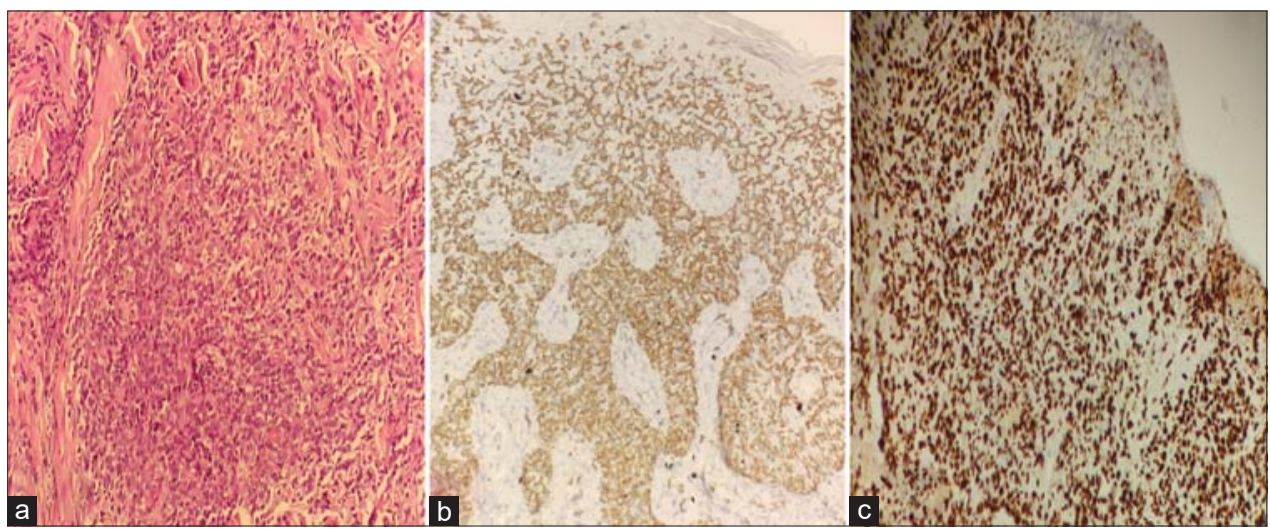

Figure 1 (a) Dermal infiltration by large cells; (b) positive CD8 ${ }^{+}$marking by almost all tumor cells; (c) Ki-67 marking by $80 \%$ of the tumor cells.

In contrast to classical $\mathrm{CD}^{+}{ }^{+}$mycosis fungoides, $\mathrm{CD}^{+}$ $\mathrm{MF}$ is a rare cytotoxic phenotype constituting about $5 \%$ of all cases of MF [1]. It belongs to the first group of primary cytotoxic cutaneous lymphomas (PCCL) with a good prognosis, an indolent course, and a slow progression of the lesions over several years [2]. However, rare cases with a more aggressive course have been reported in the literature [3]. The main differential diagnosis of aggressive $\mathrm{CD} 8^{+} \mathrm{MF}$ is an aggressive epidermotropic cutaneous $\mathrm{CD} 8{ }^{+}$lymphoma that is a rare cutaneous lymphoma with a poor prognosis due to rapid extracutaneous dissemination [4].

The prognosis of the $\mathrm{CD}^{+}$subtype of mycosis fungoides (MF) is controversial. More studies are necessary to clarify this subject.

\section{Consent}

The examination of the patient was conducted according to the principles of the Declaration of Helsinki.

The authors certify that they have obtained all appropriate patient consent forms, in which the patients gave their consent for images and other clinical information to be included in the journal. The patients understand that their names and initials will not be published and due effort will be made to conceal their identity, but that anonymity cannot be guaranteed.

\section{REFERENCES}

1. Kalay Yildizhan I, Sanli H, Akay BN, Sürgün E, Heper A. $\mathrm{CD}^{+}$cytotoxic mycosis fungoides: A retrospective analysis of clinical features and follow-up results of 29 patients. Int J Dermatol. 2020;59:127-33.

2. Martinez-Escala ME, Kantor RW, Cices A, Zhou XA, Kaplan JB, Pro B, et al. CD8+ mycosis fungoides: A low-grade lymphoproliferative disorder. J Am Acad Dermatol. 2017;77:489-96.

3. Jonak C. CD8+ mycosis fungoides: A wolf in sheep's clothing? $\mathrm{Br}$ J Dermatol. 2019;181:1126-7.

4. Robson A, Assaf C, Bagot MC, Burg G, Calonje E, Castillo C, et al. Aggressive epidermotropic cutaneous CD8+ lymphoma: A cutaneous lymphoma with distinct clinical and pathological features. Report of an EORTC Cutaneous Lymphoma Task Force Workshop. Histopathology. 2015;67:425-41.

Copyright by Asmae Abdelmouttalib, et al. This is an open access article distributed under the terms of the Creative Commons Attribution License, which permits unrestricted use, distribution, and reproduction in any medium, provided the original author and source are credited.

Source of Support: Nil, Conflict of Interest: None declared. 